\title{
CARACTERIZAÇÃO GENÉTICA E DISTRIBUIÇÃO GEOGRÁFICA DO VÍRUS RÁBICO ISOLADO DE BOVINOS NO ESTADO DE MATO GROSSO, BRASIL
}

\author{
G.C.A. Matta ${ }^{1 *}$, D.L.P. Nociti ${ }^{1}$, A.A.B. Carvalho ${ }^{2}$, S.I. Samara ${ }^{2}$, \\ F.H. Ito ${ }^{3}$, T. Sakai ${ }^{4}$, T. Itou ${ }^{4}$, G. Sato ${ }^{4}$, Y. Kobayashi ${ }^{4}$, N. Mochizuki ${ }^{4}$
}

${ }^{1}$ Universidade Federal de Mato Grosso, Faculdade de Agronomia e Medicina Veterinária, Av. Fernando Correa da Costa, s/nº, CEP 78060-900, Cuiabá, MT, Brasil. E-mail: giovana.almeida@agricultura.gov.br

\section{RESUMO}

\begin{abstract}
Foram caracterizados, geneticamente e geograficamente, o sequenciamento parcial da nucleoproteína (gene N) de 53 isolados do vírus da raiva (VR) originários do Estado de Mato Grosso, Brasil. Os isolados de bovinos, que se encontravam no grupo do VR relacionado a morcegos hematófagos, foram posteriormente subdivididos em sete subgrupos genéticos. Estes subgrupos foram distribuídos em regiões de terras planas, com alguns subgrupos separados por formações de pequenas montanhas e hidrografia. Estes resultados indicam que a raiva em bovinos é derivada de diversas variantes regionalmente definidas, o que sugere que sua distribuição geográfica está relacionada as populações de morcegos hematófagos.
\end{abstract}

PALAVRAS-CHAVE: Vírus da raiva, bovinos, análise filogenética, análise geográfica.

\section{ABSTRACT}

GENETIC CHARACTERIZATION AND GEOGRAPHIC DISTRIBUTION OF RABIES VIRUS ISOLATES FROM CATTLE IN MATO GROSSO, BRAZIL. A total of 53 rabies virus (RV) isolates originating from cattle in the state of Mato Grosso, Brazil, were genetically characterized. Partial nucleoprotein gene sequences of these isolates were phylogenetically and geographically analyzed. Cattle isolates, which clustered with the vampire bat related RV group, were further subdivided into 7 subgroups. These subgroups were distributed widely in lowland regions, with some subgroups separated from each other by small mountains and hydrographical features. These results indicate that cattle rabies is derived from several regionally-defined variants, which suggests that its geographical distribution is related to that of the vampire bat population.

KEY WORDS: Rabies virus, cattle, RT-PCR, phylogenetic analysis, geographical analysis.

\section{INTRODUÇÃO}

A raiva é uma das mais sérias e disseminadas zoonoses do mundo. Descrita pelo menos há quatro milênios, é uma das doenças infecciosas mais antigas que se tem conhecimento (RUPPRECHT et al., 2001). Causa uma encefalomielite aguda e fatal, resultante principalmente da transmissão do vírus pela mordida de um animal doente (ACHA; SZYFrES, 1986; KAPLAN; KoprowsKI, 1980). Estudos bioquímicos têm demonstrado que, além do RNA, o vírus é composto estruturalmente por cinco proteínas: uma RNA polimerase RNA-dependente (proteína L de190KDal), responsá- vel pelas atividades enzimáticas necessárias para transcrição e replicação do RNA viral, uma glicoproteína de superfície (proteína G de 65 a 80 KDal), uma nucleoproteína (proteína $\mathrm{N}$ de 57 a 62 KDal), que é um dos maiores componentes do vírus e a maior proteína interna do complexo helicoidal (WUNNER, 2002). É fosforilada em um único sítio, exercendo a função de proteger a RNP (TORDO, 1996) e é a mais importanteno processo de encapsidação(TORDO et al., 1986). Uma fosfoproteína (proteína P, NS ou M1 de 35 a 41 KDal), que é uma proteína multifuncional eum componentechavedocomplexoRNA polimerase associada ao virion, sendo uma proteína regulatória

${ }^{2}$ Universidade Estadual Paulista, Faculdade de Ciências Agrárias e Veterinárias, Jaboticabal, SP, Brasil.

${ }^{3}$ Universidade de São Paulo, Faculdade de Medicina Veterinária e Zootecnia, Laboratório de Zoonoses Virais, São Paulo, SP, Brasil.

${ }^{4}$ Universidade de Nihon, College of Bioresource Sciences, Laboratório Central de Diagnóstico, Kanagawa, Japão. *Programa de Pós-Graduação em Medicina Veterinária. 
na replicação do genoma viral, e uma proteína matriz (proteína M ou M2 de 22 a 25 KDal) (BourHy et al., 1990; SMITH, 1996; TORDO, 1996; WunNER, 2002). Seu principal genótipo é o VR clássico, de distribuição mundial e, atualmente, oúnico genótipo isoladonas Américas. Os reservatórios doVRvariam deacordocoma regiãoonde o vírus ocorre, mas cães e morcegos hematófagos (Desmodusrotundus) sãoosmaiores transmissoresdoVR no Brasil. Morcegos vampiros, amplamente distribuídosna América Latina, transmitemoVRaosherbívoros esãoreconhecidoscomoimportantefontedeinfecçãodo vírus da raiva em herbívoros (ARELLANO-SOTA, 1988). Estudos epidemiológicos moleculares baseados na técnica de RT-PCR (Transcriptase Reversa seguida de Reação em Cadeia pela Polimerase), associados ao sequenciamento deDNA, são usuais para classificação de vírus de animais, incluindo o VR, e ajudam a estabelecer um melhor entendimento das relações epidemiológicas (HAAs, 1997). Entre os genes do VR, o geneN, em particular, temsidoempregadocomsucesso em estudos de epidemiologia molecular devido a suas sequências serem mais conservadas, e seus produtos são então mais utilizados para fins de diagnóstico (SACRAMENTOet al., 1991). Neste trabalho, para definir as características epidemiológicas da raiva, foram realizadas análises filogenéticas e os achados foram comparados com a distribuição geográfica de 53 amostras de VR isolados de bovinos.

\section{MATERIALEMÉTODOS}

Foram selecionadas 53 amostras de tecido encefálico provenientes de bovinos machos e fêmeas de diversas idades e cruzamentos raciais, coletadas no ano de 2007, para realização de tipificação genética molecular. Dentre as amostras analisadas, 37 pertenciam ao bioma Cerrado, 12 ao Pantanal e 4 à Amazônia. Todas as amostras foram diagnosticadas positivas para raiva pelo teste de imunofluorescência direta (IFD) com o uso de conjugado antirrábico policlonal marcado pelo isotiocionato defluoresceína (GoldWASSER; KissLing, 1958) e a prova biológica de inoculaçãointracerebral em camundongos(IIC)(DEAN et al., 1996).

Osácidos nucleicos foram extraídos com okit diagnóstico comercial QIAamp® Viral RNA (QIAGEN, Hilden, Alemanha), seguindo o protocolo do fabricante. A extraçãofoi realizada no Laboratório deZoonoses Virais da Faculdade de Medicina Veterinária e Zootecnia da Universidade de São Paulo, USP.

A técnica de RT-PCR e a purificação dos produtos amplificados foram realizadas conforme o procedimento publicado por KoBAyAsH et al. (2006), onde foi realizada a amplificação da sequência de 203 nucleotídeos da nucleoproteína $\mathrm{N}$, quecorrespondeas posições 109-311 da amostra PV (Pasteur Virus). Os produtos amplificados foram confirmados através de eletroforese em gel agarose 1,5\%, com coloração de brometo de etídio. Os produtos amplificados e purificado do RT-PCR foram enviados ao Laboratório CentraldeDiagnóstico, doCollegeofBioresourceSciences, da Universidade de Nihon, Fujisawa, Kanagawa, Japão, para fins de sequenciamento, análises genética e filogenética. Os estudos dos alinhamentos de nucleotídeos entre as amostras foram realizados pelo software Clustal X (THOMPSON et al., 1997), e a árvore filogenética foi construída utilizando-se o método de SAITOU; NeI(1987),comoalgoritmodeNeighbor-Joining e o vírus Mokola foi utilizado como grupo externo. A significância estatística das filogenias construídas foi estimada por meio da análise de bootstrap de 1.000 replicações. Os grupamentos com valores debootstrap maiores que $70 \%$ foram interpretados como evidência de grupamento filogenético e a homologia entre as sequências de nucleotídeos foi identificada usando-se o software BIOEDIT(Hall, 1999). As origens geográficas do sequenciamento de isolados do VR de bovinos foram plotadas em nível municipal dentro do Estado de Mato Grosso, utilizando-se o software MapInfo ProfissionalGIS(ver.8.0softwareMapInfoJapanK.K., Tokyo, Japan). Por meio desses resultados, foram deduzidas as linhagens das variantes do vírus da raiva encontradas no Estado de Mato Grosso.

\section{RESULTADOS}

Os resultados dessa análise indicaram que as 53 amostras pertenciamaogenótipo1 dogênero Lyssavirus, com identidade entre os 203 nucleotídeos de pelo menos $83,7 \%$. Todos os 53 isolados foram identificados como VR relacionado a morcegos hematófagos, que possui várias linhagens filogenéticas. Os VR analisados foram agrupados em sete subgrupos caracterizados pela alta identificação dos nucleotídeos (Fig. 1). Alocalizaçãogeográfica dos isolamentos pertencentes aos sete subgrupos é demonstrada na Figura 2. Os municípios de Barra do Bugres, Cuiabá e Mirassol D'oeste, onde se encontram 3 das 5 amostras do subgrupo A, encontram-seem regiões debaixas altitudes (entre 129 e262 m). Com relaçãoao relevo, Barra do Bugreséformado pela Baixada do RioParaguai, sendo cortado por algumas pequenas serras. Cuiabá encontra-se no Planalto Guimarães e na depressão do rio Paraguai, assim como Mirassol D’oeste. Já Matupá e Itaúba, onde foram encontradas as duas outras amostras do subgrupo A, localizam-sena região da Floresta Amazônica, a altitudes entre $300-400$ m, na região do Planalto Residual do Norte de Mato Grosso, sendo ainda Itaúba delimitada pelas Serras do Cachimbo e dos Caiabés. Itiquira, único município representante 
do subgrupo B, localiza-se na região do Planalto Taquari-Itiquira, a 520 m dealtitude. Os municípios de PrimaveradoLesteeParanatinga, ondeforam coletadas duas das três amostras representantes do subgrupo C, localizam-se em regiões mais elevadas (600-636 m), sendoquePrimavera encontra-sena regiãodo Planalto dos Guimarães e Paranatinga na depressão Interplanáltica Paranatinga. A terceira amostra pertenceao Município deCuiabá. Os municípios deSanto Antonio de Leverger e Nossa Senhora do Livramento, onde foram localizadas as linhagens pertencentes ao subgrupo D, são próximos e localizam-se na Depressão do Rio Paraguai, a baixas altitudes, variando entre 140-171 m. O subgrupo E foi representado por duas amostras localizadas no Município de Jangada, também localizado na depressão do Rio Paraguai e com altitude de $200 \mathrm{~m}$. O subgrupo F, também um novo grupo isolado, érepresentado por uma única amostra encontrada no Município de Várzea Grande, também situadona depressão do Rio Paraguai, comaltitude de $185 \mathrm{~m}$. Osubgrupo $\mathrm{G}$ foi representado por 31 amostras, em sua maioria no sul do Estado, e duas amostras localizadas na região norte. A maioria das amostras encontra-se no Município de Mirassol D'oeste (10

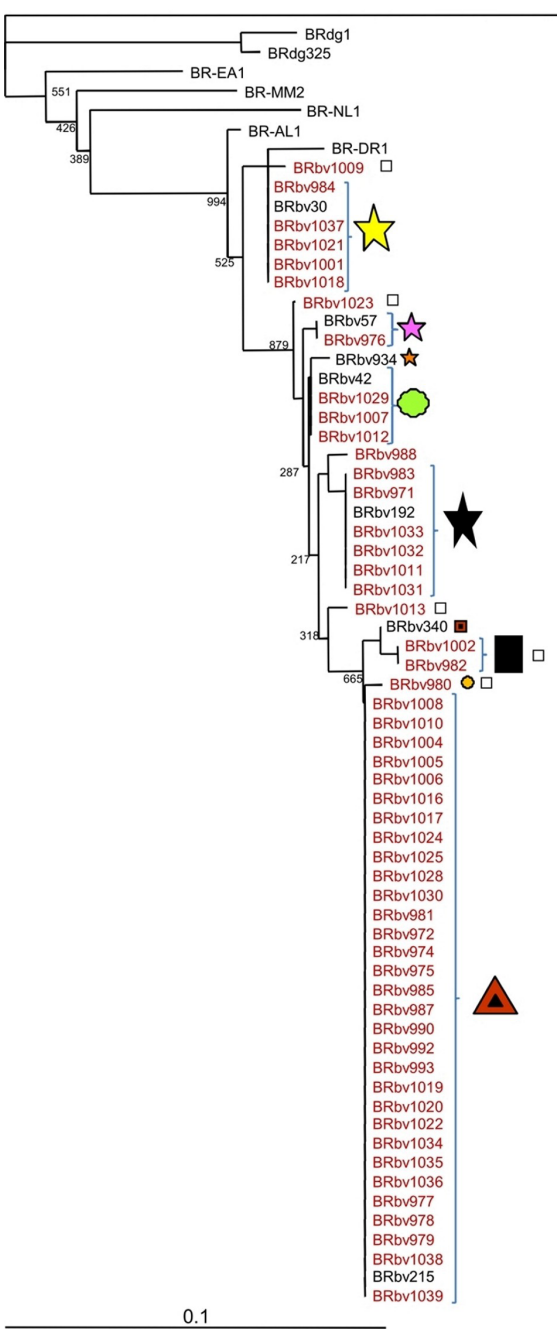

amostras) que, juntamente com os municípios vizinhos Barra do Bugres (5 amostras), Porto Estrela (2 amostras), e Lambari D'oeste (1 amostras), está localizado na região da Baixada do Rio Paraguai, com altitude média de $130 \mathrm{~m}$, sendo que Barra do Bugres e Porto Estrela possuem algumas serras em seu relevo. Outros dois municípios que possuem amostras do subgrupoGsãoDiamantino (1 amostra)e Alto Paraguai (1 amostra), com altitudes de 225 e 252 m, respectivamente. AltoParaguai está localizadonocentrodeuma Província Serrana e pertence à Bacia do Prata. Já Diamantino encontra-se na região do Planalto dos Parecis. Com uma amostra, o Município de Alto Araguaia localiza-se mais a sudeste do Estado, na região do Planalto Taquari-Itiquira, com altitude de $662 \mathrm{~m}$. Mais ao sul, na região do Pantanal Matogrossense, à altitude de $118 \mathrm{~m}$, encontra-seo Município de Cáceres com 7 amostras pertencentes também ao subgrupoG. AoNorte, encontram-seos municípios de Alta Floresta (1 amostra) e Colíder (1 amostra) do subgrupo G. Ambos os municípios localizam-se em regiãodeplanalto, comaltitudes deaproximadamente 300 m. Próxima à Colíder encontra-se a Serra do Cachimbo.
Fig. 1 - Árvore filogenética baseada na sequência parcial do gene N. O vírus Mokola foi usado como grupo externo. As amostras de VR isoladas neste trabalho estão indicadas em vermelho. As demais amostras são de artigos anteriores (КовауASH et al., 2005; КовAYASH et al., 2006). Novos grupos distinguidos a partir de $203 \mathrm{pb}$ do gene $\mathrm{N}$. 


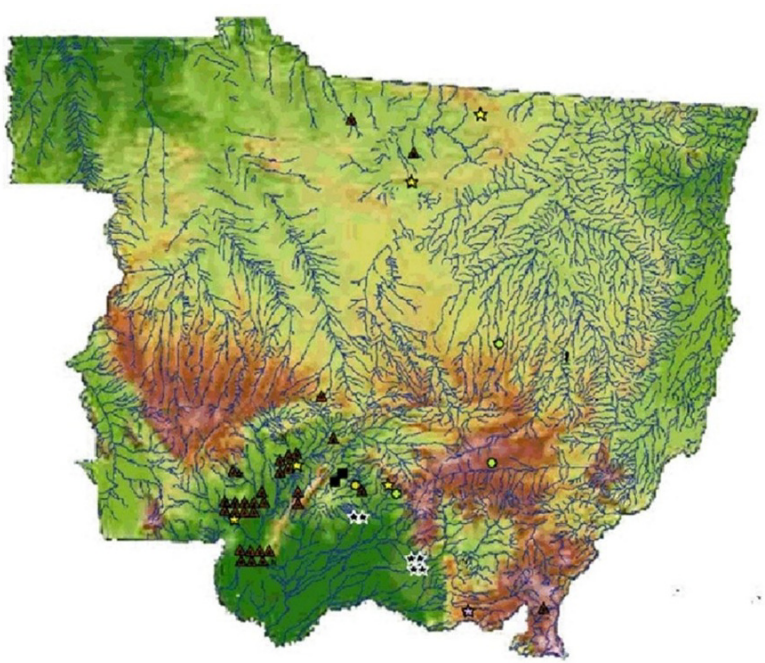

Fig. 2 - Distribuição geográfica das amostras isoladas de bovinos divididas em 7 subgrupos na análise filogenética. Os símbolos correspondem à Figura 1.

As amostras BRbv1009, BRbv 1023 e BRbv 1013 não se encaixaram em nenhum dos subgrupos, sendo novos grupos distinguidos a partir deste estudo.

\section{DISCUSSÃO}

As análises filogenéticas do gene $\mathrm{N}$ demonstraram que as amostras isoladas de bovinos estavam geneticamente relacionadas ao grupo do VR de morcegos vampiros, de acordo com FAVORETTO et al. (2000), que também estudaram amostras brasileiras usando anticorpos monoclonais e concluíram que $100 \%$ das amostras isoladas de bovinos pertenciam à variante do D. rotundus.

O padrão de distribuição dessas linhagens difere quanto à origem geográfica, o que sugere que as características epidemiológicas das linhagens do VR estejam associadas à ecologia das populações de morcegos hematófagos. Apesar de formarem colônias relativamente estáveis, os morcegos hematófagos costumam visitar regularmente abrigos vizinhos, o que de certa forma promove uma comunicação indireta entre a maioria das colônias de uma determinada área (LORD, 1988). Em razão deste aspecto da ecologia do $D$. rotundus, a disseminação da raiva nesta espécie é mantida através do contato entre indivíduos infectados de uma colônia eindivíduos suscetíveis de outra (McColl et al., 2000; LORD, 1988). A distribuição das variantes encontradas neste estudo tendem a ser separadas por regiões de montanhas, estando de acordo com observações de KOBAYASHI et al. (2006) e Velasco-Villa et al. (2006). De acordo com FerReIRA (2001), o Estado de Mato Grosso possui poucas áreas de elevadas altitudes, sendo predominantes as regiões de planícies e depressões, o que facilita a dissemi- nação do vírus pelas colônias de morcegos hematófagos. Segundo RomijIN et al. (2003), estes morcegos podem voar longas distâncias em busca de comida em extensas regiões, disseminando o vírus em um curtointervalo de tempo. As amostras dos grupos A e G foram encontradas tanto na região sul como na região norte do Estado, apesar de possuir diversos rios entre as duas regiões e de bacias hidrográficas diferentes, o que não impediu o deslocamento do vírus. Esses achados, corroborados por Romisin et al. (2003) sugerem que o VR relacionado a morcegos hematófagos tendea se espalhar por regiões de terras baixas. Osubgrupo B, representado somente por uma amostra, encontra-se na região de planalto a sudeste do Estado, de altitudes mais elevadas (520 m). Este fato pode explicar o isolamento desta variante específica nesta região. As três amostras do subgrupo C encontram-se também em áreas de planalto mais elevadas (em torno de $600 \mathrm{~m}$ ), sendo que Cuiabá também possui região de depressão com altitudes mais baixas (165 m). As variantes pertencentes ao subgrupo D estão localizadas na região da Planície do Pantanal Mato-Grossense, região de baixas altitudes e que possui uma população de quirópteros pouco estudada. Talvez pelo regime de cheias e vazantes específico dessa região, esta variante tenha se tornado endêmica nesta região. As amostras do subgrupo E foram encontradas somente no município de Jangada, a $72 \mathrm{~km}$ da capital. Trata-se de uma região de baixas altitudes $(200 \mathrm{~m})$, porém circundada pela Serra das Araras, o que pode favorecer o isolamento desta linhagens somente nesta região. As linhagens representante do subgrupo F está localizada em região de baixas altitudes ( $185 \mathrm{~m}$ ) ebem próxima aos subgrupos C, D, E e G tornando bem possível a existência desta variante nesses municípios vizinhos. As amostras BRbv 1009, BRbv 1013 e BRbv 1023, que não foram enquadradas em nenhum destes subgrupos por se tratarem de novas linhagens assim como as dos subgrupos D e E, que estão localizadas na região do Pantanal, no Município de Rondonópolis e em Nova Olímpia, a baixas altitudes (em torno de $200 \mathrm{~m}$ ) sendo que Rondonópolis fica próxima à Serra de São Jerônimo, que assim como o Pantanal, serve debarreira para a disseminação destas linhagens.

O presente estudo indica que a raiva bovina é derivada de diversas linhagens que não estão regionalmente bem definidas dentro do Estado de Mato Grosso. Por outro lado, as linhagens estudadas por KoBAyASH et al. (2006), em diversos Estados do Brasil, estavam regionalmente bem definidas. Estes achados implicam que a distribuição geográfica da raiva bovina é dependente da população de morcegos hematófagos, porque o maior transmissor da raiva bovina são os morcegos hematófagos (ARELLANO-SOTA, 1988). A diversidade genética entre linhagens foi 
atribuída a aspectos relacionados a ecologia dos morcegos e a variações topográficas do habitat. Consequentemente, parece queo VR podeestarcirculando por populações demorcegos quehabitamáreas contínuas e, apesar da distribuição das variantes mudarem lentamente, barreiras naturais como montanhas podem ter um papel importante na delimitação de focos de raiva, resultando em variantes regionalmente diferenciadas do VR. KoBAYASH et al. (2006) observaram que as variantes do VR relacionadas aos morcegos hematófagos localizadas em regiões montanhosas estavam relacionadas com a altitude. Já em outro estudo realizado por KoBAYASHI et al. (2008), muitas linhagens foram observadas dispersas por sobre potenciais barreiras, movendo-se das regiões de altas para baixas altitudes. A distribuição das linhagens pelos biomas também foi observada neste trabalho,assim como em KовAYashi et al. (2008). Grande número de amostras analisadas neste estudo foi encontrada ao longo de rios, e muitas amostras caracterizadas como sendo da mesma linhagem estavam distribuídas ao longo do mesmo rio. Os morcegos hematófagos movimentam-se seguindo a trajetória dos rios, devido a abundância de abrigos e cavernas nas suas margens, onde geralmente são observados surtos de raiva em bovinos (LoRD, 1988). Consequentemente, a presença de rios e refúgios adequados foi reconhecida como importante consideração no delineamento da incidência e disseminação da raiva dos bovinos transmitida por morcegos hematófagos. Grande parte das amostras analisadas neste estudo foi isolada deáreas adjacentes ligadas por rios, estando de acordo com observações epizoóticas da raiva bovina, sendo que muitas amostras caracterizadas como mesma linhagem estavam distribuídas ao longo do mesmo rio. Esses achados sugerem que a tendência de distribuição de linhagens esteja relacionada ao comportamento dos morcegos hematófagos, estando a disseminação do VR relacionada a sua migração.

A existência de numerosas espécies, distribuídas amplamente no território brasileiro, torna a história natural da raiva em morcegos uma questão ainda a esclarecer, assim como a manutenção de linhagem do VRem determinadas espécies demorcegosinsetívoros e determinando a transposição para outras espécies animais (spill-over) (RomIINetal.,2003). Considerando o grande número de espécies de morcegos existentes no Brasil, é provável que existam linhagens do VR ainda desconhecidas (КовAYASHI et al., 2006).

\section{CONCLUSÕES}

Os resultados da análise filogenética indicaram que, no Estado de Mato Grosso, a raiva bovina é causada por diversas linhagens do VR que não estão regionalmente bem definidas. Estes achados implicam que a distribuição das variantes está intimamente relacionada à movimentação dos morcegos hematófagos. Foi também observada que a distribuição do VR relacionado a morcegos hematófagos está relacionada à altitude, e sua transmissão parece ser mais prevalente em regiões de baixas altitudes e são limitadas pela distribuição de serras e montanhas. Estes achados sugerem que as características epidemiológicas da raiva bovina transmitida por morcegos hematófagos podem ser influenciadas por fatores topográficos e geográficos das regiões onde os rebanhos são mantidos, tanto quanto a aspectos relacionados a ecologia dos morcegos. Estes achados, por meio do isolamento geográfico de variantes do VR, contribuem para o conhecimento das características epidemiológicas do VR transmitido por morcegos hematófagos. Portanto, propõe-se que esses fatores sejam considerados na elaboração de programas e medidas de prevenção e controle por parte dos órgãos oficiais de defesa sanitária, na tentativa de atenuar a disseminação da raiva bovina transmitida por morcegos hematófagos.

\section{REFERÊNCIAS}

ACHA, P.N.; SZYFRES, B. Zoonosis y enfermedades transmissibles communes al hombre y a los animales. 2.ed. Washington: Organización Panamericana de la Salud, 1986. p.502-526.

ARELLANO-SOTA, C. Biology, ecology and controlo of the vampire bat. Reviews of Infections Diseases, v.10, p.615-619, 1988. Suplemento 4.

BOURHY, H.; SUREAU, P.; TORDO, N. From rabies to rabies-related viruses. Veterinary Microbiology, v.23, p.115-128, 1990.

DEAN, D.J.; ABELSETH, M.K.; ATANASIU, P. Fluorescent antibody test: In: MESLIN, F.X.; KAPLAN, M.M.; KOPROWISKI, H. (Ed.). Laboratory techniques in rabies. Geneva: World Health Organization, 1996. p.88-95.

FAVORETTO, S.R.; MATTOS, C.C. de; CARRIERI, M.L.; MATTOS, C.A. de; CUNHA, E.M.S.; AGUIAR, E.A.C.; SILVA, L.H.Q.; SODRÉ, M.M.; SOUZA, M.C.A.M.; KOTAIT, I. Caracterização de variantes no Brasil e países vizinhos. In: SEMINÁRIO INTERNACIONAL DE RAIVA, 2000, São Paulo. Anais. São Paulo: Instituto Pasteur, 2000. p.59-61. Resumo 7.2.

FERREIRA, J.C.V., Mato Grosso e seus municípios. 19.ed. Cuiabá: Secretaria de Estado da Educação, 2001. 660p. 
GOLDWASSER, R.A.; KISSILING, R.E. Fluorescent antibody staining of street and fixed rabies virus antigens. Proceedings of the Society for Experimental Biology and Medicine, v.98, p.219-223, 1958.

HAAS, L. Molecular epidemiology of animal virus diseases. Journal of Veterinary Medicine, séries B, v.44, p.257-272, 1997.

HALL, T.A. Bioedit: a user-frindly biological sequence alignment editor and analysis program for Windows 95/98/NT. Oxford: Oxford University Press, 1999. p.95-98. (Nucleic Acids Symposium Series n.41).

KAPLAN, M.M.; KOPROWSKY, H. Rabies. Scientific America, v.242, n.1, p.104-113, 1980.

KOBAYASHI, Y.; OGAWA, A.;SATO, G.;SATO, T.; ITOU, T.; SAMARA, S.I.; CARVALHO, A.A.; NOCITI, D.P.; ITO, F.H.; SAKAI, T. Geographical distribution of vampire bat-related cattle rabies in Brazil, The Journal of Veterinary Medical Science, v.68, n.10, p.1097-1100, 2006.

KOBAYASHI, Y.; SATO, G.; MOCHIZUKI, N.; HIRANO, S.; ITOU, T.; CARVALHO, A.A.B.; ALBAS, A.; SANTOS, H.P.; ITO, F.H.; SAKAI, T. Molecular and geographic analyses of vampire bat-transmitted cattle rabies in central Brazil. BMC Veterinary Research, v.4, p.44, 2008.

LORD, R.D. Control of vampire bats. In: GREENHALL, A.M.; SCHIMIDT, U. (Ed.). Natural history of vampire bats. Florida: CRC Press, 1988. p.215-226.

McCOLL, K.A.; TORDO, N.; SETIÉN, A.A. Bat lyssavirus infections. Revue Scientifique et Technique OIE, v.19, n.1, p.177-196, 2000.

ROMIJIN, P.C., van der HEIDE, R.; CATTANEO, C.A.; SILVA, R.C. van der POEL, W.H., Study of lyssaviruses of bat origin as a source of rabies for other animal species in the state of Rio de Janeiro, Brazil. The American Journal of Tropical Medicine and Hygiene, v.69, p.81-86, 2003.

RUPPRECHT, C.E.; STOHR, K.; MEREDITH, C. Rabies. In: WILLIANS, E.S.; BARKER, I.K. (Ed.). Infections diseases of wild mammals. Ames: Iowa State University Press, 2001. p.3-36.
SACRAMENTO, D.; BOURHY H.; TORDO, N. PCR Technique as an alternative method for diagnosis and molecular epidemiology of rabies virus. Molecular Cells Probes, v.5, p.229-240, 1991.

SAITOU, N.; NEI, M. The neighbor-joining method: a new method for reconstructing phylogenetic trees. Molecular Biology and Evolution, v.4, p.406-425, 1987.

SMITH, J.S. New aspects of rabies with emphasis on epidemiology, diagnosis, and prevention of the disease in the United States. Clinical Microbiology Reviews, v.9, n.2, p.166-176, 1996.

THOMPSON, J.D.; GIBSON, T.J.; PLEWNIAK, F.; JEANMOUGIN, F.; HIGGINS, D.G. The Clustal X Windows interface: flexible strategies for multiple sequence alignment aided by quality analysis tools. Nucleic Acids Research, v.25, n.24, p. 4876-4882, 1997.

TORDO, N. Characteristics and molecular biology of the rabies virus. In: MESLIN, F.X.; KAPLAN, M.M.; KOPROWSKY, H. (Ed.). Laboratory techniques in rabies. Geneva: World Health Organization, 1996. p.28-51.

TORDO, N.; POCH, O. ERMINE, A.; GÉRARD, K. Primary structure of leader RNA and nucleoprotein genes of the rabies genome: segmented homology with VSV. Nucleic Acids Research, v.14, n.6, p.2671-2683, 1986.

VELASCO-VILA, A.; ORCIARI, L.A.; JUÁREZ-ISLAS, V.; GOMES-SIERRA, M.; PADILLA-MEDINA, I.; FLISSER, A.; SOUZA, V.; CASTILLO, A.; FRANKA, R.; ESCALANTE-MAÑE, M.;SAURI-GONZÁLEZ, I.; RUPPRECHT, C.E. Molecular Diversity of rabies viruses associated with bats in Mexico and other countries of the Americas. Journal of Clinical Microbiology, v.44, n.5, p.1697-1710, 2006.

WUNNER, W.H. Rabies virus. In: JACKSON, A.C.; WUNNER, W.H. (Ed.). Rabies. San Diego: Academic Press, 2002. p.23-77.

Recebido em 8/5/09

Aceito em 9/12/09 